\title{
A ESCRITURA CORRENTE DE MARGUERITE DURAS*
}

\author{
Celina Moreira de Mello \\ Universidade Federal do Rio de Janeiro
}

\begin{abstract}
RESUMO
A produção textual de Marguerite DURAS atinge na década de 80 a perfeição formal que caracterłza a depuração de um estilo não mais preso às injunções de qualquer engajamento. Uma rápida leitura de Agatha (1981) e de L'Amant (1984) nos permite tentar definir, com a autora, o que seria sua escritura corrente: um corpo-a-corpo com o texto à procura da música.
\end{abstract}

No jogo de leitura e resistência que o texto literário propōe ao crítico, a Teoria do Texto aparece, ao propor ferramentas conceituais precisas tais como escritura, produção textual, intertextualidade, enquanto expressão teórica adequada para que se avalie a produção literária contemporânea.

Numa visão de literatura que torna fúteis as distinções de gênero, centrada sobre o texto e a produção textual, desaparece a barreira entre obra literária e obra crítica, entre escritor e exegeta, entre escrever e ler. Desfiando o seu tecerse de inúmeros fios - linguagem e inconsciente, mas também vida do autor, gênero, época, visão de mundo, etc. ... - a Teoria do Texto compreende, a um só tempo, a obra literária, a leitura crítica que o escritor tem de sua obra e a escritura do crítico que, por si só, constitui igualmente uma obra.

Discurso crítico e discurso literário, mesmo considerando-se uma sincronia absoluta de todos os textos, a qual aponta para a intertextualidade, apresentam-se como contemporâneos. $\mathrm{E}$ portanto dentro deste recorte teórico que trataremos dos textos de Marguerite DURAS, Agatha e L'Amant, publicados em 1981 e 1984 respectivamente, sem contudo separar,

\footnotetext{
- Fragmentos de Marguerite Duras: - Texto a sua travessia, tese de Doutoramento defendida em 1986 na Faculdade de Letras/UFRJ - Bemiologia.
} 
artificialmente tais textos do conjunto da obra desta escritora'.

Autora contemporânea, sua obra é vastíssima, variada e complexa, constituindo um polo de atração inegável para leitores e críticos. Compreende também uma extensa filmografia, a qual exerce seu encanto desde seu primeiro sucesso, Hiroshima mon amour (1959). Por outro lado, há constantes referências que a integram ao Nouveau Roman e, mais recentemente, alguns fazem de Marguerite Duras uma escritora do Novo Feminismo. Acrescente-se a isto uma franja importante de entrevistas e depoimentos da própria autora sobre sua obra, em que vemos, como uma constante, a recusa em integrar-se a grupos, a dobrar-se a programas, a aceitar etiquetas, a proferir verdades definitivas ou dar explicaçōes conclusivas.

Uma certeza, entretanto, escrever constitui para a autora, desde sempre, uma paixão. Influências temáticas e estilísticas, assim como tomadas de posição políticas e estéticas foram, aos poucos, abandonadas. Desde o primeiro momento, contudo, afírma-se, absoluto, o desejo de escrever, o escrever do desejo e o escrever do desejo de escrever. E embora recuse o rótulo de "escritora do desejo"2, é a consciência de ser este desejo plural uma transgressão do projeto contrário de sua mãe, do projeto contrário da sociedade e do projeto contrário da própria instituição literária, que faz dela uma "pária"3. Escritora "difícil", "hermética", cujo valor só foi reconhecido por muitos em 1984, com o "Goncourt", maior prêmio literário francês, para L'Amant, o qual lhe havia sido recusado em 1950 para Un barrage contre le Pacifique. Mais de trinta anos depois, não tendo conseguido calar este discurso, a sociedade reconhece seu lugar, reiterando suas ambiguas relações com a Literatura. Curiosamente, L'Amant retoma, numa escritura confessional, tema, personagens e situações que faziam a trama de Un barrage contre le Pacifique. Texto que se oferece ao leitor com a aparência inocente e fácil de uma narrativa autobiográfica, L'Amant é, na verdade, uma etapa a mais de uma obra que procura, a cada texto, aprofundar a misteriosa alquimia do fazer literário.

Posição ambígua também a desta escritora, que existe pelo texto e cujos textos se fazem na tentativa de destruí-1o: dando-lhe sua voz, dando-lhe corpos, confrontando-o à música, narrando e definindo como poemas tais narrativas, dizendo e nesse dizer afirmando a nostalgia do silêncio.

Agatha, cujas dimensōes modestas dissimulam um texto que para a autora é capital, é um texto privilegiado sob vários aspectos. Nele cruzam-se uma leitura de L'homme sans qualités de Musil, do espaço proustiano em A l'ombre des 
jeunes filles en fleur e da vivência da autora. A circularidade textual denuncia a falsidade de qualquer pretensão realista. O sentido do texto não preexiste a ele, senão por ele é produzido. De igual modo, coloca-se, neste texto, a relaçāo entre sujeito e linguagem. Não é o sujeito que escreve o texto, senão este que o escreve e o que se escreve é o desejo interdito: 0 incesto.

A presença da música, a forma dialogica e a força das metáforas do corpo, outros fios condutores de Agatha, traduzem-se, com maior presença física, embora com menor força poética, no filme de Marguerite Duras, Agatha ou les lectures illimitées (1981).

Na obra de Marguerite Duras, há uma evolução que tende para este texto, definido pela autora como "escritura corrente" , técnica que se apura, definitivamente, em L'Amant. Até $1958, M$. D. escreve romances, narrativas, peças de teatro, roteiros cinematográficos; até 68 , há uma procura de novas formas de expressão; após 68, a busca de uma "rigorosa liberdade" torna-se mais radical. Nas inumeras entrevistas em que Marguerite Duras disserta sobre o seu fazer literário, verifica-se a consciência que a autora tem deste processo.

O corpo-a-corpo com o que chama de "pura escritura" parece-lhe a forma mais transgressiva de luta politica e faz desaparecer de seu projeto de escritura qualquer "engajamento", no sentido tradicional da palavra, o que inclui o combate feminista.

Na produção textual de M. D., alguns pontos insistem. O primeiro deles é a questão do sujeito. Se na primeira fase de sua obra, a escritora parece saber perfeitamente quem produz o seu texto, a partir de Le Ravissemente de Lol V. Stein (1964), desaparece a noção de uma produção controlada, controlável, a impressão que se tem é que não é mais M. D. quem escreve os textos, mas os textos de $M$. D. que se escrevem. Ela é apenas o "lugar" da escritura:

M. D.: . . Je suis encore aujourd'hui dans l'incapacité de vous dire comment j'ai écrit Agatha, le Ravissement de Lol V. Stein, le Vica-consul, Hiros' hlima... Je suis dans l'impossibilité totale de vous dire comment ça s'est fait, ça s'est passé. Mais quand je les relis, je suis étonnée, je me dis: "Qu'est'ce qui m'est arrivé?" Je ne comprends pas très bien. C'est comme ça écrire. Il faut le dire très simplement. On n'est pas complètement responsable de ce qu'on écritt. 
Em 1984, numa entrevista com o jornalista Bernard Pivot, a autora manifesta uma clara consciência deste processo que Madeleine ALLEINS" chama de mediúnico: "Je dis les choses comme elles arrivent chez moi, je fais le geste, oui, c'est comme ca, comme elles m'attaquent, si vous voulez, comme elles m'aveuglent"i.

Algumas situaçōes, como a mendiga de Savannakhet que vendeu o seu bebê, e alguns personagens, como Anne-Marie Stretter e o Vice-cônsul, sua própria mãe e seus irmãos, que encontramos não somente em Agatha e L'Amant mas em vários outros textos, provêm na sua maioria de lembranças de sua infância. Outras personagens, como Lol V. Stein, percorrem um difícil caminho para se transformarem em texto, outras ainda, como Aurélia Steiner produzem o próprio texto e a autora coloca-se, então, numa humilde posição de escuta, a fim de transcrevê-lo.

O segundo ponto é uma metáfora recorrente quando a autora se refere a sua produção textual. Trata-se de sombra, de um topos escuro, interior, feito de experiências ("vécu.) que se deve esvaziar, iluminar, no momento em que se escreve, no movimento de passar para o papel um texto que, de certa forma, preexiste ao ato de escrever.

Este preexistir não deve ser confundido com a volição, com a intencionalidade atribuída ao escritor na concepção tradicional de literatura. Trata-se, na verdade, da idéia de que tudo é escritura, tudo é texto:

La mer est complètement écrite pour moi. C'est comme des pages, des pages pleines, illisibles à force d'être écrites, d'être pleines d'écriture ${ }^{8}$.

E preciso dar, contudo, transcrever numa página, antes branca, este "texto". O momento em si da escritura corresponderia, então, para M. D. a uma compulsão, à impossibilidade de não passar por esta operação final, uma "transgressāo" que ela chama de "filtro".

O sentido se organizará a posteriori, produto de uma escritura, de uma busca, às vezes dolorosa:

Je disais: quand je fais un livre, je suis dans le trouble total, dans l'incertitude et dans l'inconnu. Je suis donc devant. Je ne sais pas ce que le livre va être, je ne sais pas ce que je vais écrire ${ }^{\mathrm{i0}}$.

Quando fala de sua obra, a autora não o faz, em geral, para esclarecer tal ou qual passagem ou ainda para se referir a um projeto qualquer a que aquela corresponderia, mas, 
interrogando o outro, o leitor, e deixando patente que seus significantes escapam a seu controle e, muitas vezes, deixam-na perplexa. Assim, a "terceira personagem" de Détruire, dit-elle - "Je voudrais bien qu'on l'élucide, ça"11 — ou a origem da particularissima marginalidade social de suas personagens - "Mais je ne sais pas, voilà, c'est ça qui est étrange"12.

$O$ ato de escrever corresponderia a um precisar dizer, muito mais do que a um querer dizer, com o risco de enlouquecer, mas um dizer intransitivo, sem desejo de posse de um significado. Esta intransitividade remeteria a uma valorização do significante: significantes geradores de sentidos ${ }^{13}$.

São significantes que desencadeiam, na autora, o processo de escritura. Numa entrevista sobre L'Amant, ela explicita este processo que parte de palavras que geram as frases, que se constroem, assim como o próprio livro, a partir de tais palavras:

Il y a les mots de la phrase. Et il y a les mots du livre. Le mot "désert" scande le livre tout entier. Le mot "amant" aussi. Les mots "blanc", "blanche" aussi, le blanc des maisons des postes de brousse, le blanc des murs dans l'ombre du fleuve, des maisons de Blancs, et celui, éclatant, de la peau de l'enfant, de la jeune fille blanche. La Chine aussi envahit le livre... C'est vrai que la Chine vient jusqu'à capter Hélène Lagonelle, son corps, qui à son tour envahit le livre. C'est à le relire que je m'en aperçois. Il y a une métonymie constante, incessante, dans "l'Amant" 14 .

Metonimia que desloca o sentido da personagem para seu espaço, num processo análogo ao da escritura. Escrevemos com o corpo, fora do corpo, para fora do corpo e o texto torna-se, então, um lugar de nosso corpo. Isto faz com que o tema de um texto seja a imagem do escritor, seu reflexo especular, seu ego ("moi"), como precisa a autora:

J'ai su plus tar que ce n'était pas moi maintenant qui avais alimenté le livre ni trouvé l'ordre de son déroulement, c'était en moi. Quelqu'un que je croyais ne plus connaitre et que j'avais laissé faire. Pour tout vous dire, je crois qu'il n'y a pas de grand roman ni de roman "véritable" en dehors de soi. C'est moi, l'histoire"t. 
O corpo-a-corpo com a escritura intransitiva define, então, o escritor e, paradoxalmente, obriga a crítica a repensar este personagem. Assim, quando a autora afirma, em nome desta intransitividade da escritura, que "Sartre não escreveu"1". A esse respeito, lembremos a distinção feita por Roland BARTHES entre escritores e escreventes ("écrivains" e "écrivants"). Ambos trabalham com o discurso, o escritor, entretanto, faz da palavra um fim em si e não um meio, como o escrevente. $O$ escritor não comunica respostas mas interroga o porquê do mundo, colocando a questão do sentido. Para o escrevente, o discurso, mais ou menos trabalhado, como um instrumento mais ou menos afinado, veicula uma doutri. na, transmite uma mensagem, engaja uma obra (uma vida). O posicionamento político do escrevente, tal como o define a literatura engajada do após-guerra na França, corrente que tem em Sartre, sem dúvida, um de seus representantes mais expressivos, separa aqueles que escrevem em dois grupos. Escritores seriam, pois, aqueles que consideram seu combate muito mais profundo e eficaz, já que travado no texto e não pelo texto ${ }^{1 i}$.

Ao afirmar, como numa provocação, que Sartre não escreveu, Marguerite Duras reitera sua recusa de qualquer engajamento institucional - mesmo no que se chama Literatura - , recusa esta que afirma em sua obra um poder mais destruidor, uma vez que expressa a força do desejo.

Ora, o desejo, na sua postura ética que é a constante procura do gozo, põe em perigo o social, o qual só se mantém de reprimi-lo. $\mathrm{E}$ embora discordando de Madeleine ALLEINS ${ }^{\top}$, , quando esta afirma ser a obra de M.D. composta de textos/etapas de uma busca da verdade, parece-nos correto caracterizar esta obra, sobretudo no que se refere a sua produção mais recente, como o desenho, traço por traço, de diversas figuras que se relacionam pelo desejo e que, por isto, fascinam autor e leitor.

Sem teorias sobre o romance, sem qualquer discurso teórico e recusando todo o engajamento, numa certa fase de sua obra, a autora parece identificar-se com a produção literária do Novo Feminismo: o "discurso orgânico" ou escritura feminina.

O M.L.F., de inspiração americana, introduzira profundas alterações no campo literário e editorial francês. 1974, ano especialmente fecundo, é marcado por uma grande quantidade de publicaçōes "feministas", "femininas", de mulheres, sobre as mulheres ${ }^{19}$.

Por entre textos que se indefinem entre a reportagem e o manifesto e romances que se escrevem com o corpo da mulher - menstruação, gravidez, calor e umidade uterinos, 
frases ritmadas como um parto - dois livros se destacam, que fundamentam teoricamente esta produção: Speculum de l'autre femme ${ }^{20}$, de Luce IRIGARAY, o qual num discurso psicanalítico desvela o desejo e a sexualidade "outras" da mulher, e Les parleuses ${ }^{21}$ de Marguerite DURAS e Xavière GAUTHIER, que interrogam a especificidade feminina na própria escritura.

Do ponto de vista do crítico, na opiniāo de $M$. D., a escritura feminina só é considerada se souber limitar-se a uma temática "feminina":

Alors, l'homme rassuré, prend le livre de cette femme et commence à légiférer. Enfin, c'est-à-dire: elle ne fait qu'ajouter à une littérature, à une littérature qui lui sert de terreau. Si elle ne parle pas de ces H.L.M., habitant un H.L.M., et de ses six gosses, il fait le flic. Il censure. De quoi se mêle-t-elle? 2

Sua obra frustra esta exigência, centrada que é na temática do desejo, e do desejo da mulher. A tensāo erótica de seus textos não explode no orgasmo. O desejo, cada vez mais aparece como sendo "plural", não inteiramente monopolizado por duas personagens, mas estilhaçando o casal, o par romântico tradicional e seus habituais correlatos: a noção de posse exclusiva e de fidelidade.

Para Xavière GAUTHIER, a escritura feminina, na obra de $M$. D. aparece com os seguintes traços: $:^{33}$

1. Um discurso feito de silêncio, escrito com o corpo;

2. Um discurso transgressor que brinca no limiar da loucura;

3. Um discurso que, em seu ritmo e seu movimento, se funde com ritmos e movimentos da natureza;

4. Uma passividade que não se confunde com doçura ou renúncia, mas que é gerada na revolta;

5. Uma hiância, a-social, atravessada, mais do que preenchida por amantes e filhos. Amor sempre interdito, fecundidade marcada pela culpa e pela dor.

Predominância da palavra, em detrimento da sintaxe, eliminaçāo de artigos, pouca importância do tempo gramatical, lacunas, ausência de cores, vozes que parecem atravessar as personagens, tudo isto compõe o que M.D. chama de "um campo de experimentaçäo"-4, constitui os "pontos de estofo":" em que, na escritura, passam o sentido da proximi. dade da loucura, da fusão com a natureza e o espaço habitado, da passividade-revolta, da força da inércia face ao social e da travessia do desejo - o feminino. 
Isto, entretanto, nos facultaria afirmar uma escritura feminina?

Certas mulheres tomam a palavra para expressar novos significados; esta "escritura do corpo" não parece, contudo, ter criado uma "escritura" que se distinguisse de outras escrituras, embora os textos tenham, em geral, uma mesma marca feita de simplicidade, efeito criado pela escolha de um registro familiar, mais apropriado à expressão de seu universo.

Algumas escritoras tentam fazer explodir as formas, cortando o ritmo, recriando a pontuação, fazendo jorrar a sensualidade das palavras, reinventando vocábulos, confundindo pronomes. Mas este fluxo vem sempre marcado pela repetição (ciclos biológicos?), recurso que é constantemente utilizado por M.D. e que funciona como uma chave de leitura para seus textos. A repetiçāo corresponderia ao próprio movimento de experimentação a que alude a autora:

C'est ça, ça va. Ça n'avance pas. Ça va nulle part, ça bouge ${ }^{20}$.

"Ca bouge". O inconsciente em movimento, o movimento da linguagem, da força do imaginário lutando contra o simbólico, para escapar à loucura ou ao silêncio, tentando dizerse no corte, criando uma escritura.

Mas já em 1977, em seu Entretien avec Michelle Porte, a autora manifesta-se consciente de não integrar o grupo de escritoras do Novo Feminismo e recusa o chamado "discurso orgânico":

Les femmes parlent de leurs corps comme ça, tout le temps, je ne veux plus en entendre parler, du tout ${ }^{2 i}$.

Embora continue a considerar que uma certa escritura só é possível para a mulher escritora, M. D. não afirma, de modo algum haver uma literatura feminina. E em 1981 ela declara:

Je ne sais pas. On parlait d'écrire. Je ne crois pas qu'il $y$ ait une littérature de femme. Il $y$ a des femmes ${ }^{28}$.

... Je crois que ce n'est pas qualitatif. Ce n'est pas de l'énergie masculine ni de l'énergie féminine. C'est une énergie à venir, blanche, neutre. C'est peut-être celle-lả qui habite les femmes depuis une dizaine d'années, partout dans le monde ${ }^{2: 3}$. 
Podemos, a esse respeito, observar uma evolução na obra da autora, pois tendo partido de um fazer literário que chama de "masculino", que se rompe com Moderato Cantabile em 1959, e depois de ter adotado alternadamente pontos de vista da narração masculino e feminino, é somente a partir de 1979, nos textos de Aurélia - Aurélia Steiner I (Melbourne), Aurélia Steiner II (Vancouver) e Aurélia Steiner III (Paris) - que a mulher se posiciona como sujeito da escritura:

Música do nome Aurélia, o texto do filme aparece também como uma meditação sobre a escritura. A fórmula, amplamente metafórica de "escritura fílmica" recupera, aqui, seu sentido definitivo e literal.

"Eu escrevo" ("J'écris") é, como vimos, a última palavra dos dois filmes: a primeira é "eu escrevo para você" ("je vous écris")...

Pela primeira vez, na obra de Marguerite Duras tanto em seus filmes quanto em seus livros - uma mulher assume a posição de sujeito da escritura ${ }^{31}$.

Esta posição de mulher sujeito da escritura sustenta-se na situação de mulher sujeito de seu desejo. Tanto em Agatha, quanto em L'Amant, a mulher aparece como sujeito de seu desejo. Neste último, seu discurso funde-se com o da narradora que faz representar tal posiçāo - metonimicamente - pelos sapatos de baile dourados e pelo chapéu masculino. E é o gozo que faz dela sujeito de seu discurso, marcando a passagem de uma narração na terceira pessoa, para uma narração na primeira pessoa:

Elle ne le regarde pas. Elle le touche. Elle touche la douceur du sexe, de la peau, elle caresse la couleur dorée, l'inconnue nouveauté. Il gémit, il pleure. Il est dans un amour abominable.

Et pleurant il le fait. D'abord il y a la douleur. Et puis après cette douleur est prise à son tour, elle est changée, lentement arrachée, emportée vers la jouissance, embrassée à elle.

... Je ne savais pas que l'on saignait ${ }^{31}$.

A noção de escritura preferimos, então, a de escritura corrente. Aproximamos os textos de M. D., não somente da 
poesia, mas de uma partitura musical, pela possibilidade que estes nos facultam, de uma leitura paradigmática, paralelamente à evidente leitura sintagmática: a repetiçāo quase que obsessiva de certos temas, de certas situaçōes, de certas frases. Mas também pela presença primordial do silêncio, $o$ qual pontua os seus textos tão expressivamente quanto a palavra. A produção de textos reveste, muitas vezes, o caráter de um corpo-a-corpo com a lingua, para dela extrair o que furta, o que, não podendo ser dito, permanece interdito. écrit"32.

"L'écrit est beaucoup plus proche du silence que le faux

Na obra de M.D., observamos um movimento que tende para este silêncio. Seus textos despojam-se cada vez mais, de detalhes típicos de uma visāo realista e documental da literatura e suas personagens libertam-se, gradativamente, das injunções do cotidiano.

As pausas e as reticências que se repetem, insistentemente, na obra da autora, entretanto, não somente configuram uma recusa da sintaxe (metonímia do simbólico), da língua enquanto corpo de leis, mas permitem uma construção melódica, uma quase melopéia, fortemente ritmada.

Constatamos também uma crescente "oralidade" em seus textos que provém da possibilidade, que lhe foi dada pelo cinema, de dizê-los em voz alta. Aqueles que ouvem seus últimos filmes, ao ler seus textos, ouvem sua voz.

Por outro lado, mais do que temas, podemos, em sua obra, delimitar verdadeiros ciclos poéticos: para VERCIER e LECARME" ao retomar, numa escritura que afirmam ser análoga à da música, temas, personagens e lugares, M.D. criaria ciclos poéticos, entre os quais o ciclo da Indochina e o ciclo da fndia já podem ser nitidamente percebidos. Em India Song, a presença da mendiga de Savannakhet nos jar. dins da Embaixada da França na fndia, funde os dois num único ciclo.

A música, na verdade, constitui uma constante na obra da autora. Popular ou clássica, muito simples como as sete notas de Nathalie Granger ou dificilima, como as fugas de Bach cujas partituras constituem um belíssimo plano deste filme, a música atravessa praticamente todos os seus textos:

Et si vous voulez, ce chemin qu'il y a à parcourir, depuis les gammes de l'enfant, les gammes de l'enfance, ou l'enfance de l'homme, l'enfance de l'humanité, jusqu'à ce langage-là que nous ne pouvons pas décrypter, le langage de la musique, ce chemin me bouleverse ${ }^{34}$. 
A música será sempre, exceto pelo canto da mendiga de Savannakhet, representada pelo piano, instrumento que encontramos com frequiência em seus textos e em seus filmes. Fascinação e recusa, paixão e revolta, a música parece provocar em suas personagens reaçōes contraditórias e ambiguas.

São várias as personagens que recuam diante do universo da música, diante da imensa dificuldade que têm para tocar piano. Para a personagem Elle, de Agatha, a recusa do piano transforma-se em dom. Deixar de tocar piano, representa, para Elle, dar ao irmāo a música, "toute la musique à jamais"35.

Várias obras de M.D., igualmente, associam-se de modo absoluto à música, ou, mais especificamente, a uma música. A mais famosa é a música-tema do filme India Song, composta pelo músico argentino Carlos d'Alessio, assim como dois tangos, duas valsas, um rag-time, um charleston e uma rumba. Em Agatha, várias valsas de Brahms, uma das quais, nos seus primeiros acordes, lembra uma composição de Gilbert Bécaud, "Et maintenant". Em Savannah Bay (1982), ouve-se "Les Mots d'Amour", composição de Edith Piaff.

$E$ ainda o canto da mendiga de Savannakhet. Último resquício de lucidez e de memória. Último laço que a prende à sua aldeia natal, a sua infância, a sua mãe. Último vestígio de sua condição humana. Sinal de esquecimento e de memória. Mise en abyme da própria obra da autora, naquilo que representa em valores absolutos, de encanto, de resistência, de evocação de uma humanidade distante no tempo e no espaço, e em sua atormentada relação com a figura mater$\mathrm{na}^{30}$.

A música, que Marguerite DURAS compara à floresta "c'est lié, la forêt et la musique, quelque part"3i — atravessa todos os seus textos, enquanto silêncio e discurso se alternam, na tentativa de dizer o desejo.

A autora, em entrevista já citada, ao jornalista que colo. ca a questão do gênero de L'Amant, evoca uma composição musical:

Je l'ai écrit mesure par mesure, temps par temps, sans jamais essayer de trouver une correspondance plus ou moins profonde entre eux, les temps.

... Il n'y a de composition que musicale. Dans tous les cas, c'est ce reajustement du livre qui est d'ordre musicalss. 
Este processo de escritura, que atinge em L'Amant seu esplendor máximo, seria desencadeado por certas palavras a partir das quais as frases e o texto se constroem, numa metonímia constante que M.D. define como escritura corrente:

Quand on passe de la malfaisance de mon frère à la description du ciel équatorial, de la profondeur du bleu, de la fomentation du mal à celle de l'infini, c'est ça. Et cela sans qu'on le remarque, sans qu'on le voie. L'écriture courante, c'est ça, celle qui ne montre pas, qui court sur la crête des mots, celle qui n'insiste pas, qui a à peine le temps d'existeris.

Escritura corrente, como uma água que corre ou o correr de dedos pelas teclas de um piano. Em Un barrage contre le Pacifique, a personagem da mãe havia feito do piano seu ganha-pão. Tocava num cinema em que na tela se projetavam filmes mudos e de seus dedos pareciam não somente jorrar as músicas, mas também as imagens. Ora, em entrevista feita para a televisão, quando o jornalista Bernard Pivot pede-lhe que defina sua escritura, M. D., referindo-se igualmente a esta escritura corrente, faz o gesto de quem... tocasse piano.

\section{REFERENCIAS BIBLIOGRAFICAS}

1 DURAS, Marguerite. Agatha. Paris, Minuit, 1981 e - L'amant. Paris: Minuit, 1984.

2 cf.—- PIVOT, Bernard. Apostrophes; entrevista a Bernard Pivot na estação de T.V. Antenne 2, Paris, 28-09-84.

3 cf:—— GAUTHIER, Xavière. Les parleuses. Paris: Minuit, 1979. p.186.

4 cf.—; PIVOT. op. cit.

5 LAMY, Suzanne; ROY, André. Marguerite Duras à Montréal. Montréal: Spirale Solin, 1984. p.23.

6 cf. ALLEINS, Madeleine. Marguerite Duras; médium du réel. Lausanne: L'Age d'Homme, 1984. p.173.

7 cf. DURAS \& PIVOT. p. cit.

8 - PORTE, Michelle. Les licux de Marguerite Duras. Paris: Minuit, 1977, p.91

9 LAMY; ROY. op. cit. p.58

10 Ibidem, p.21.

11 DURAS; GAUTHIER. op. cit. p.47.

12 Ibidem, p.57.

13 cf. BARTHES, Roland. Ecrivains et écrivants. In: - Essais critiques. Paris, Seuil, 1964. p. 147-154. 
14 LE NOUVEL OBSERVATEUR. Paris, n. $.^{\circ} 1038,1984$. p.53.

15 Ibidem.

16 cf. DURAS \& PIVOT. op. cit.

17 cf. BARTHES, Roland. Sollers ecrivain. Paris: Minuit, 1979.

18 cf. ALLEINS, M. op. cit.

19 Femmes, une autre écriture? MAGAZINE LITTERAIRE. Paris, n. 180, jan v. 1982 . p.17.

40 IRIGARAY, Luce. Speculum de l'autre femme. Paris: Minuit, 1974.

21 DURAS \& GAUTHIER. op. cit.

22 Ibidem, p.37.

23 Marguerite Duras. MAGAzINE LITTERAIRE. Paris, n. ${ }^{\circ} 158$, mars 1980. p.16-19.

24 cf. DURAS \& GAUTHIER. op. cit., p.11-18.

25 cf. VALLEJO, Américo; MAGALHĀES, Lígia C. Lacan: operadorcs de Ieitura. São Paulo, Perspectiva, 1981. s.v. sentido, efeito de. p.123-124.

26 cf. DURAS \& GAUTHIER. op. cit., p.15-16.

27 Le camion suivi de Entretien avec Michelle Porte. Paris, Minuit, 1977. p.105.

28 LAMY \& ROY. op. cit. p.51.

29 Ibidem, p.69.

30 BORGOMano, Madeleine. L'écriture filmique de Marguerite Duras. Paris, Albatros, 1985. p.161.

31 DURAS, M. L'Amant. op. cit. p.50. O grifo é nosso.

32 LAMY \& ROY. op. cit., p.58.

33 cf. LECARME, Jacques; VERCIER, Bruno. La littérature en France depuis 1968. Paris, Bordas, 1982. p.285.

34 DURAS; PORTE. op. cit. p.30.

35 DURAS, M. Agatha. op. cit., p.29.

36 cf. o minucioso estudo da personagem da mendiga que encontra. mos em MARINI, Marcelle. Territoires du féminin avec Mar. guerite Duras. Paris, Minuit, 1977.

37 LE NOUVEL OBSERVATEUR. op. cit. p.52.53.

38 Ibidem, p.53. 